\title{
Quality of the master's program: factors and regulatory framework
}

\author{
Natalia Vlasova, Dmitriy Karkh \\ Ural State University of Economics, 620144, 8 Marta Str., 62, Ekaterinburg, Russia
}

\begin{abstract}
The quality of educational programs and the assessment criteria is a debatable point. Universities pay special attention to the management and evaluation of the master's program quality to improve competitiveness. Approaches to an external and internal assessment of the quality of master's programs have changed over the past 20 years in Russia. The paper analyses the approach to internal university monitoring of the master's programs, taking into account external requirements and all stakeholders' opinions. The analysis of the preferences of employers and students allowed us to determine the parameters of internal monitoring of the quality of master's programs. Focused interviews with representatives of local government bodies allowed to identify the blocks of disciplines that need to be further integrated into the master's program in public administration. It is emphasized that the approach to quality assessment should be more flexible in order to respond to the challenges of the external environment.
\end{abstract}

\section{Introduction}

The current state of development of the Russian educational system is characterized by the need to improve the quality of the educational programs. This concerns the degree of employers' satisfaction with the quality of graduates' training and the need to increase the competitiveness of Russian universities in the world. All stakeholders of the educational process have taken steps to improve the quality of education in recent years. The government in the framework of the national project "Education" adopted a Federal project "Export of education", whose goal is ensuring the global competitiveness of Russian education, the entry of the Russian Federation among the 10 leading countries in quality of education. Also new approaches are being developed to strengthen the quality of the Russian education system. The interaction of educational organizations, quality assurance organizations, employers, and their associations, as well as public sectors that carry out activities in the field of education, is expanding and taking new forms.

However, there remains the problem of the concept of the quality of education, the factors that affect the quality of education. Discussions about the factors and criteria for the quality of higher education have been going on for a long time. When developing approaches and criteria for internal quality monitoring of the master's program, it is necessary to be guided by the requirements of Russian legislation, take into account the opinions of employers, students and teachers, as well as predict future global and local changes that may affect the necessary qualities of graduates. The pandemic has 
dramatically changed the learning environment, accelerated the introduction of ubiquitous online learning, and further actualized the need for a digital component in master's programs, including Public Administration programs.

\section{Materials and Methods}

Many factors affect the quality of education. In addition, the assessment can be carried out according to different parameters. The main causes that determine the diversity of definitions of «quality education» can be attributed to the multidimensional nature of quality of education (quality of results; quality of opportunities educational systems that ensured results; quality of the educational process and so on) [1].

The quality of the educational program can be considered from different points of view:

- meeting the educational needs and demands of the individual, society, and the state;

- the quality of the processes, activities and results of the implementation of the educational program;

- the effectiveness of educational activities (effectiveness in terms of the quality of the educational program, the pedagogical, managerial, organizational and economic efficiency).

We will highlight the features of assessing the quality of education:

- multi-criteria quality of education. The quality of education is evaluated in various subjects according to numerous sets of criteria (quality of results, quality of the educational process, quality of the subjects of education);

- assessment of quality of education runs a variety of stakeholders - students, alumni, and parents are the customers of education in a particular educational institution, society, public authorities, employers, representatives of the education system (teachers, organizers of education); All this leads to a certain bias and variability estimates.

- multilevel of educational outcomes (quality of training of graduates of various educational levels).

All elements and actors of educational process are important for its quality. The authors note the crucial importance of teachers ' involvement and motivation for the quality of teaching [2]. It is possible to detail the entire learning process, including the selection of applicants, different types of training, assessment procedures, a variety of social activities, etc. For example, Lucander and Christersson distinguished the five phases of the process for quality assurance of assessment [3].

Students' motivation and their involvement in research and social activities are also important factors of students' satisfaction. The ability of students to carry out research and involvement in teaching-learning process had the high influence in decreasing student dissatisfaction [4]. The introduction of the research element in the learning process is important not only for the formation of students' research competencies, but also for increasing university competitiveness as a research center [5].

There is also an external and internal assessment of the quality of the educational program [6].

Internal evaluation is conducted by the educational organization. The main objectives of the internal assessment system are to determine whether the education provided meets the needs of individuals and society; to ensure the openness and accessibility of information about the university educational activities; to provide stakeholders with reliable information; to improve the competitiveness of educational programs.

The achievement of the objectives of the internal system of education quality assessment is implemented by performing the following tasks in the field of education quality assessment:

- Identification of factors influencing the quality of education. 
- Analysis of the quality of implementation of normative documents in the field of education, acts of the rector, academic council of the university, faculty, etc.

- Formation of a common approach to the criteria for the quality of education and approaches to its measurement.

- Formation of a system of analytical indicators that allows to analyse and to increase the quality of education.

- Development and implementation of an effective system for monitoring, analysing and evaluating the quality of students training.

- Analysis of educational services quality and assessment of conditions of educational process (determination of the degree of compliance of the conditions of implementation and realization of educational process and educational programs to the Federal requirements).

- Evaluation of effectiveness of educational programs, methods and technologies; evaluation of quality management education.

- Development of forms of participation of stakeholders in the management and improvement of the quality of education.

- Preparation and adoption of informed management decisions on improving the quality of education, the effectiveness of the university - information support of the process of making management decisions on the problems of improving the quality of education.

A particular role in internal assessment is assigned to the assessment of the staff professional competencies within the framework of general professional competencies, educational, and research activities.

The system for receiving feedback on the quality of the implementation of educational programs includes regular surveys of students, teachers, and employers. Close communication with employers is an important condition for the quality of training, which is confirmed by many researchers [7].

This can include such procedures as assessment of the quality of teaching, surveys of members of state examination commissions, graduate and employer surveys.

A feedback system on the quality of graduate training should be based on general principles:

- Regularity of receiving feedback.

- Combining different ways to get feedback from the main groups (employers and graduates).

- Comparability of the information received (standardized questionnaires).

The performance of the internal evaluation of the quality of education is shown in the following:

- Forming the most objective evaluation of the quality of training of students according to the results of mastering educational programs.

- Improving the structure and updating the content of educational programs implemented at the university.

- Improving the resource support of the educational process at the university.

- Improving the competence and skill level of the university scientific and pedagogical staff involved in the implementation of educational programs.

- Increasing the motivation of students.

- Strengthening the interaction of the university with relevant enterprises, institutions, and organizations on improving the educational process.

- Increasing the responsibility of the heads of structural divisions for the quality of training of students.

- Unification of approaches to the independent assessment of the quality of training of students through the standardization of assessment tools and procedures. 
- Providing the structural divisions of the university with objective information about the level of training of students to make informed management decisions on the problems of improving the quality of educational services.

- Identification of factors affecting the quality of educational services in order to take timely measures aimed at improving the efficiency and quality of the university's educational activities.

- Improving students' self-organization with objective data on their academic achievements.

- Ensuring the openness and accessibility of information on the quality of educational services and on the educational achievements of students for external and internal users.

If national accreditation is a prerequisite for the work of the university, then international accreditation is used in cases where the university seeks to increase its awareness and competitiveness in the world market. Blanco argued that symbols associated with accreditation or ranking is important for the university [8].

\section{Results and Discussion}

The quality assessment system in the Russian Federation is based on a combination of various evaluation mechanisms:

- External and internal procedures for evaluating the educational process and its results.

- Procedures for receiving feedback from various participants in educational relations about the quality of educational services (such stakeholders include, first of all, students, graduates, and key employers).

The procedures for evaluating the quality of educational programs in Russia are divided into external and internal. Internal evaluation procedures and tools include:

- Regular self-examinations of educational programs, including quality assessment according to special criteria.

- Annual self-examination of the educational organization as a whole (the results of reports on the results of self-examination are used, among other things, in monitoring the activities of universities of the Ministry of Education and Science of the Russian Federation).

- Procedures for independent evaluation of students ' educational results.

- Final state certification of final year students of all educational programs-it is carried out by an authoritative commission, which includes external experts from third-party educational organizations, representatives of employers.

External procedures and institutions include:

- Different types of accreditation and certification.

- Independent examination of educational programs, including with the involvement of international experts.

Accreditation is a process of recognizing the quality of education following the norms and quality standards of the accrediting organization. If these standards are set by the state (through the federal state educational standards), then accreditation is called state.

International accreditation is the recognition by a reputable international organization of the compliance of an educational organization, a set of its programs, or a separate educational program with certain international standards of quality of education.

By the Russian legislation, obtaining state accreditation for educational institutions, in contrast to licensing, is optional and takes place on an application basis, but the public status of an accredited educational institution is higher than that of an uncredited one (especially for non-state institutions). The legislation contains mechanisms for motivating educational institutions to obtain state accreditation, primarily due to the benefits and rights of students provided for by law. 
A list of 11 indicators is used for the accreditation of higher education institutions in Russia, which now can be considered sufficient for an integrated assessment of the effectiveness of the university and its attribution to the type of institutions of higher professional education and one of the specific groups. As higher education develops and socio-economic conditions change, the system of indicators may change.

The current system of indicators for institutions of higher professional education includes quantitative and qualitative indicators that are evaluated by experts in the course of an external assessment of an educational institution. The system of indicators also takes into account the dynamics of the development of the educational institution in a certain period: the results over the past five years and the prospect of their stability in the coming years.

State accreditation acts as the main mechanism for guaranteeing the quality of education. At the same time, the quality of education is considered not only as a philosophical category but also as an existing property of an educational institution - a set of necessary and sufficient signs and criteria that allow us to establish the quality of education.

If a public organization and/or a professional community set the quality standards, such accreditation is called public (professional-public).

Depending on whether the quality of an individual program or the entire university (its division) as a whole is recognized, accreditation can be programmatic or institutional.

Public (professional-public) accreditation can be carried out by both Russian and international accreditation organizations and agencies.

A special type of accreditation is certification - in this case, the educational program is recognized as meeting the quality standards and leading the training of such a level that is necessary for its graduates to receive professional certificates (either with subsequent passing of certification exams without additional training or with exemption from them).

Independent expertise is a variant of external evaluation of the quality of educational programs, a kind of "audit", which is carried out by an expert commission consisting of professionals recognized in this scientific and/or subject area. Often, the selection of experts and the organization of expertise is taken over by an external organization.

Based on these principles the monitoring of Master's degree programs was introduced in the Ural State University of Economics. The monitoring system includes the following indicators:

- International and professional accreditation.

- Availability of evaluation materials for the current and intermediate certification.

- The existence of assessment materials for the competences.

- Compliance of the evaluation criteria with the Federal requirements.

- International component (attraction of foreign staff, coursed delivering in English).

- Strategic partnership with the employer.

- The number of teaching staff, trained at enterprises

- The number of faculty from among managers and employees, strategic partners.

- Staffing (share of $\mathrm{PhD}$; share of young teachers up to 35 years).

- The number of simulators, licensed programs, and other software products aimed at improving the practical skills of students.

- The number of disciplines implemented using distance learning technologies and electronic educational resources.

- The percentage of students who are satisfied with the quality of the implementation of the program (determined by regular questionnaires).

- Students' participation in the scientific activities (conferences, workshops, etc.). Students' publications activity. 
- Implementation of project activities initiated by the employer in the scientific and educational sphere, with the students' participation.

- Availability of laboratories, the number of disciplines implemented with their use.

- Number of R \& D contracts.

The monitoring section on distance education was strengthened, partly due to existing experience and global trends, and partly due to the reality of the pandemic $[9,10]$.

The results of monitoring should be taken into account when updating master's programs.

When analyzing certain master's programs, general changes in the world and in the country should be taken into account, so that the program meets the most modern requirements.

Our focus was the Master's degree programs in public administration in the Ural State University of Economics. The content of the programs was determined based on Russian standards and requirements, taking into account foreign experience [11-13].

Digitalization is changing the principles and approaches of public administration in the modern world $[14,15]$. There is the federal project "Digital Public Administration" within the framework of the National Project "Digital Economy" in the RF (until 2024).

This regulatory framework, as well as in-depth interviews with representatives of local and regional administrations, identified the need to strengthen the digital competencies of graduates. When reviewing the structure of the master's program in public administration, it is necessary to strengthen all aspects of digitalization, adding following program modules:

- Digital technologies and platform solutions in public administration.

- Working with open data.

- Cloud technology for efficient, transparent and productive governance.

- Digital Security.

- Smart region and smart city.

- Digital technologies for public participation in governance.

- Government services digitalization.

It is planned to develop new master's programs: "Digital Governance" or "Public Administration in the Digital World".

\section{Conclusion}

A comprehensive educational concept requires an all-comprehensive strategy for quality assurance.

In accordance with the Russian legislative framework employers, their associations may carry out professional and public accreditation of professional education programs as well as organizations authorized by them. At the same time, the quality and level of training of graduates must meet the requirements of professional standards.

The internal assessment of the quality of educational programs allows quick response to various changes.

When developing and updating educational programs, it is necessary to take into account new trends, including digitalization in all spheres, including education. The pandemic has rapidly and universally changed educational technologies and is gradually leading to the introduction of new approaches to assessing learning outcomes.

\section{References}

1. A. Androniceanu, Adm. si Manag. Public. 25 (2015)

2. L. Sharma, M. Srivastava, J. Appl. Res. High. Educ. 12, 4 (2019) 
3. H. Lucander, C. Christersson, Qual. High. Educ. 26, 2 (2020)

4. M. Arefi, M. Heidari, G. S. Morkani, K. Zandi, World Appl. Sci. J. 17, 3 (2012)

5. Y. Cai, Rev High Ed. 40, 4 (2017)

6. M. Seyfried, P. Pohlenz, Eur. J. High. Educ. 8, 3 (2018)

7. A. Zehrer, C. J. Mössenlechner, Teach. Travel Tour. 8, 1 (2008)

8. G. L. Blanco, A. S. Metcalfe, Rev High Ed. 43, 3 (2020)

9. H. Abuhassna, W. M. Al-Rahmi, N. Yahya, M. A. Z. M. Zakaria, A. B. M. Kosnin, M. Darwish, Int. J. Educ. Technol. High. Educ. 17, 1 (2020)

10. N. Almusharraf, S. Khahro, Int. J. Emerg. Technol. Learn. 15, 21 (2020)

11. G. Morçöl, M. Tantardini, A. Williams, D. R. Slagle, Teach. Public Adm. 38, 3 (2020)

12. H.M. Raboca, MCCS. 2 (2011)

13. C.S. Sarrico, A.A. Alves, High Educ (Dordr). 71 (2016)

14. R. Pérez-Morote, C. Pontones-Rosa, M.Núñez-Chicharro, Technol. Forecast Soc. Change. 154 (2020)

15. J. D. Twizeyimana, A. Andersson, Gov Inf Q. 36, 2 (2019) 